В. В. Горенюк

${ }^{1}$ Вінницький національний технічний університет

Запропоновано метод синтезу та ідентифрікації моделей оптимального руху електромобіля з асинхронним електроприводом під час руху дорогою на спуск та на підйом, в якому використано той самий підхід, що запропонований під час розроблення методу синтезу та ідентифрікації моделей оптимального руху електромобіля з асинхронним електроприводом по горизонтальному відрізку дороги, але з іншими граничними умовами, з іншою процедурою їхнього використання для визначення констант, котрі мають місце у цих моделях внаслідок використання двічі операції інтегрування в процесі їхнього синтезу методом невизначених множників Лагранжа, а також з іншою процедурою реалізаиії прямого алгоритму визначення швидкості електромобіля на основі моделі його динаміки, яка у випадку руху на спуск та на підйом як параметр містить в собі ще й кут нахилу поздовжньої осі рами електромобіля до горизонтальної площини, який є величиною змінною у просторі, тож для електромобіля, що рухається, є величиною змінною і в часі, а тому вимагає вимірювання відповідним пристроєм. Показано також, що коли електромобіль виїжджає на горизонтальну ділянку дороги зі спуску чи підйому без зупинки, то для визначення констант в моделях його оптимального руху горизонтальною ділянкою дороги стають непридатними вирази, отримані раніше для випадку, коли визначались моделі оптимального руху електромобіля горизонтальною ділянкою дороги від зупинки до зупинки, оскільки змінюються граничні умови, а тому і вирази, за якими визначаються ці константи стають за своєю структурою наближеними до тих, які отримані у цій статті для моделей оптимального руху електромобіля на спуск чи підйом.

Ключові слова: електромобіль, рух на спуск та на підйом, оптимізація, модель, ідентифрікація, метод, ітераційний алгоритм.

\title{
Вихідні передумови
}

В роботі [1], використавши модель динаміки у вигляді

$$
m \frac{d V}{d t}=F_{T}-k_{0} F_{G}-k_{1} V-k_{2} V^{2},
$$

яка у відносних безрозмірних одиницях з використанням проміжних перетворень набула вигляду

$$
\frac{d v}{d \tau}=\ln \left(i+\sqrt{i^{2}+1}\right) \frac{a^{2}+b^{2}}{a^{2}+b^{2} s_{*}^{2}} s_{*}-f_{0}-f_{1} v-f_{2} v^{2},
$$

та обмеження у вигляді

$$
L=\int_{0}^{T_{i}} V d t
$$

яке у відносних безрозмірних одиницях з використанням проміжних перетворень набуло вигляду

(C) В. В. Горенюк, 2021 


$$
l=\int_{0}^{\tau_{*}} v d \tau,
$$

скориставшись методом невизначених множників Лагранжа, автори синтезували систему рівнянь

$$
\left\{\begin{array}{l}
2 a \sqrt{i^{2}+1}(1-2 \alpha i)-\left(C_{1} e^{\left(f_{1} \tau+2 f_{2} \int v d \tau\right)}-\frac{C_{2}}{f_{1}+2 f_{2} v}\right) \frac{\left(a^{2}+b^{2}\right)}{b}=0, \\
\frac{d v}{d \tau}=\ln \left(i+\sqrt{i^{2}+1}\right) \frac{\left(a^{2}+b^{2}\right)}{2 a b}-f_{0}-f_{1} v-f_{2} v^{2} .
\end{array}\right.
$$

Розв'язки системи рівнянь

$$
i=i\left(C_{1}, C_{2}, \tau\right) ; v=v\left(C_{1}, C_{2}, \tau\right)
$$

доставляють мінімум функціоналу

$$
E=\int_{0}^{T} U I d t
$$

який при синтезі моделей оптимального руху (6) електромобіля з асинхронним електроприводом горизонтальним відрізком дороги використовувався у відносних безрозмірних одиницях у вигляді

$$
e_{i}=\int_{0}^{\tau_{i}}(1-\alpha i) i d \tau,
$$

За поясненнями, що $є$ відносними безрозмірними величинами, формування яких $є$ досить громіздким, аби не захаращувати зміст цієї статті уже визначеними раніше процедурами, відсилаємо читачів до вищезгаданої роботи [1].

В роботі [2] здійснено ідентифікацію моделей оптимального руху (6) електромобіля з асинхронним електроприводом горизонтальним відрізком дороги, яка звелась до визначення констант $C_{1}, C_{2}$ як чисел $C_{1}^{*}, C_{2}^{*}$ за співвідношеннями

$$
\begin{gathered}
C_{1}^{*}=\left(\frac{2 a b}{a^{2}+b^{2}}\right) \frac{\sqrt{i_{n}^{2}+1}\left(1-2 \alpha i_{n}\right)-1}{1-e^{\left(f_{1} \tau_{l}+2 f_{2} l_{l}\right)}} ; \\
C_{2}^{*}=\left(\frac{2 a b f_{1}}{a^{2}+b^{2}}\right)\left\{\frac{\sqrt{i_{n}^{2}+1}\left(1-2 \alpha i_{n}\right)-1}{1-e^{\left(f_{1} \tau_{l}+2 f_{2} l_{l}\right)}} e^{\left(f_{1} \tau_{l}+2 f_{2} l_{l}\right)}-1\right\},
\end{gathered}
$$

отриманими з використанням граничних умов

$$
\begin{aligned}
& \left\{\begin{array}{l}
i(0)=i_{n}, \\
v(0)=0, \\
\int_{0}^{0} v(\tau) d \tau=0 ;
\end{array}\right. \\
& \left\{\begin{array}{l}
i\left(\tau_{l}\right)=0, \\
v\left(\tau_{l}\right)=0, \\
\int_{0}^{\tau_{l}} v(\tau) d \tau=l
\end{array}\right.
\end{aligned}
$$

та синтезом ітераційних процедур наближеного обчислення із заданою похибкою поточних значень відносної швидкості та відносного струму за співвідношеннями

$$
\begin{aligned}
v_{k+1} & \approx v_{k}+\frac{\left(a^{2}+b^{2}\right)}{2 a b}\left(\tau_{k+1}-\tau_{k}\right) \ln \left(i_{k}+\sqrt{i_{k}^{2}+1}\right)-\left(f_{0}+f_{1} v_{k}+f_{2} v_{k}^{2}\right)\left(\tau_{k+1}-\tau_{k}\right), \\
k & =0,1,2, \ldots ; \quad \tau_{0}=0 ; \quad v_{0}=0 ; \quad i_{0}=i_{n} ;
\end{aligned}
$$




$$
i_{k}(n)=i_{k}(n-1)-\frac{C_{3}}{n}\left\{2 a \sqrt{\left(i_{k}(n-1)\right)^{2}+1}\left(1-2 \alpha i_{k}(n-1)\right)-\left(\frac{a^{2}+b^{2}}{b}\right)\left(C_{1}^{*} e^{\left(f_{1} \tau_{k}+2 f_{2} v_{k}\left(\tau_{k+1}-\tau_{k}\right)\right)}-\frac{C_{2}^{*}}{f_{1}+2 f_{2} v_{k}}\right)\right\} .
$$

Ці ітераційні процедури побудовані за методикою, викладеною в роботі [3].

А задачею, яку поставлено у цій публікації, є задача синтезу та ідентифікації моделей оптимального руху електромобіля з асинхронним електроприводом на спусках та підйомах дороги.

\section{Розв'язання поставленої задачі}

В роботі [4], виконаній у науковій школі професора Б. І. Мокіна, вищесформульована задача уже розв'язувалась, але там мова йшла про рух на спуск та на підйом електромобіля вантажного 3 електроприводом постійного струму на основі електродвигуна з послідовним збудженням, тягова сила якого створюється зовсім за іншим законом ніж в асинхронного тягового електродвигуна, а тому отримані в роботі [4] математичні моделі оптимального руху на спуск та на підйом для цього випадку непридатні.

Але що стосується рівняння динаміки руху електромобіля, то в загальному вигляді і у цього випадку воно буде таким самим, як і в роботі [4], тобто:

- під час руху на спуск

$$
m \frac{d V}{d t}=F_{T}-k_{0} F_{G} \cos \beta+F_{G} \sin \beta-k_{1} V-k_{2} V^{2} ;
$$

- під час руху на підйом

$$
m \frac{d V}{d t}=F_{T}-k_{0} F_{G} \cos \beta-F_{G} \sin \beta-k_{1} V-k_{2} V^{2} .
$$

Порівнюючи рівняння (15) та (16) динаміки руху електромобіля, відповідно, на спуск та на підйом з рівнянням (1) динаміки його руху горизонтальним відрізком дороги, бачимо, що вони відрізняються появою двочлена

$$
\left(-k_{0} F_{G} \cos \beta+F_{G} \sin \beta\right)
$$

замість одночлена $\left(-k_{0} F_{G}\right)$ в режимі спуску, та появою двочлена

$$
\left(-k_{0} F_{G} \cos \beta-F_{G} \sin \beta\right)
$$

замість одночлена $\left(-k_{0} F_{G}\right)$ в режимі підйому. Ця трансформація рівняння (1) зумовлена тим, що сила ваги електромобіля $F_{G}$, яка під час руху горизонтальним відрізком дороги створює лише силу тертя коліс об дорогу $k_{0} F_{G}$, що протидіє силі тяги $F_{T}$, а тому входить зі знаком мінус, під час руху на спуск та на підйом з нахилом дороги до горизонтальної площини під кутом $\beta$ своїми проекціями на вісь дороги та на вісь, перпендикулярну дорозі, створює пару сил: $k_{0} F_{G} \cos \beta, F_{G} \sin \beta$, перша 3 яких є трансформованою силою тертя коліс об дорогу, а тому і в рівняння (15) і в рівняння (16) входить зі знаком мінус, а друга $є$ при спуску додатковою силою тяги, а тому входить у рівняння (15) зі знаком плюс, а при підйомі $є$ додатковою силою опору, а тому у рівняння (16) входить зі знаком мінус. Рисунок, який це схематично відображає, взятий з роботи [4], подано нижче.

Якщо, скориставшись тією ж процедурою, що приведена в роботі [1], перевести рівняння динаміки (15) i (16) до безрозмірного вигляду, то отримаємо аналог рівняння (15), що описує динаміку електромобіля на спуску дороги, у вигляді

$$
\frac{d v}{d \tau}=\ln \left(i+\sqrt{i^{2}+1}\right) \frac{a^{2}+b^{2}}{a^{2}+b^{2} s_{*}^{2}} s_{*}+f_{0}^{*} \sin \beta-f_{0} \cos \beta-f_{1} v-f_{2} v^{2}
$$

та аналог рівняння (16), що описує динаміку електромобіля на підйомі дороги, у вигляді

$$
\frac{d v}{d \tau}=\ln \left(i+\sqrt{i^{2}+1}\right) \frac{a^{2}+b^{2}}{a^{2}+b^{2} s_{*}^{2}} s_{*}-f_{0}^{*} \sin \beta-f_{0} \cos \beta-f_{1} v-f_{2} v^{2} .
$$


a)

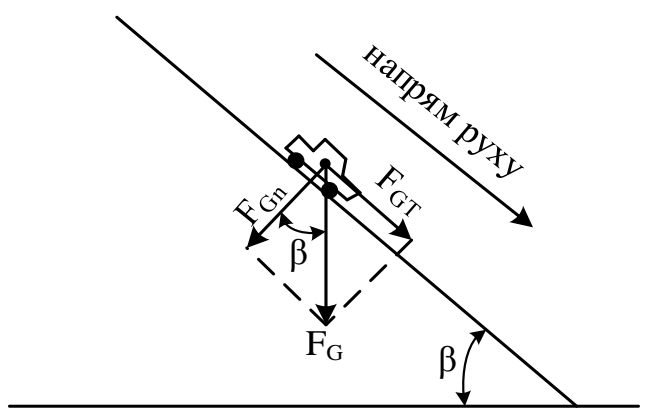

b)

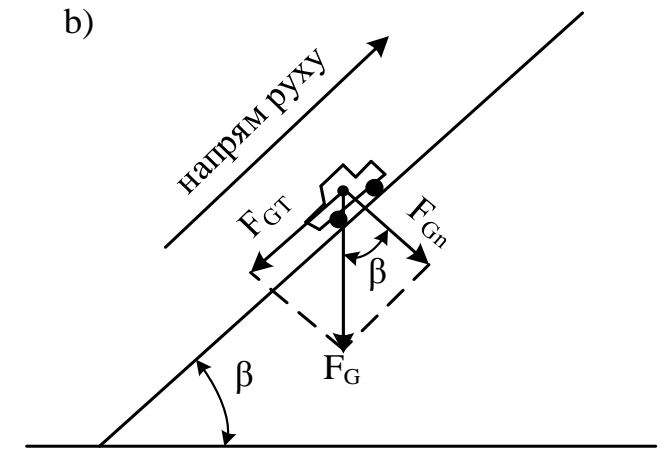

Векторні діаграми сил, створюваних силою ваги $F_{G}$ автомобіля під час руху: а — на спуск; б — на підйом

3 процедури переведення рівнянь динаміки електромобіля до безрозмірного вигляду, викладеної в роботі [1], випливає, що додатковий коефіцієнт $f_{0}^{*}$, якого немає в рівнянні (1), але який 3'явився у рівняннях (19) та (20), визначається за виразом

$$
f_{0}^{*}=\frac{F_{G} T_{M}}{m V_{H}},
$$

де $m$ - це маса електромобіля з пасажирами, $F_{G}$ - це сила ваги електромобіля, створюваної його масою, $V_{H}$ - це швидкість електромобіля, яку він розвиває на горизонтальній ділянці дороги за номінальної сили тяги, а $T_{M}$ - це електромеханічна стала часу, яка розраховується за виразом

$$
T_{M}=\frac{m V_{H}}{F_{H}},
$$

де $F_{H}$ - номінальна сила тяги електромобіля, створювана його електроприводом.

Якщо взяти до уваги, що ні двочлен (17), ні двочлен (18) не є безпосередньо залежними від $i, i^{\prime}, v, v^{\prime}, \psi, \psi^{\prime}, s_{*}, s_{*}^{\prime},-$ а саме по цих змінних, як показано в роботі [1], беруться частинні похідні в рівняннях Ейлера-Лагранжа, то навіть після уведення у функцію Лагранжа обмеження не у вигляді (2), а у вигляді (19) чи (20), все одно як розв'язок цієї системи рівнянь отримаємо перше рівняння системи (5), а тому синтезуватимемо моделі оптимального руху у вигляді (6), виходячи 3 системи рівнянь, аналогічної системі (5), в якій другим рівнянням замість рівняння (2) буде рівняння (19) для руху на спуск та рівняння (20) під час руху на підйом, тобто, моделі оптимального руху електромобіля під часу руху на спуск необхідно синтезувати з системи рівнянь

$$
\left\{\begin{array}{l}
2 a \sqrt{i^{2}+1}(1-2 \alpha i)-\left(C_{1} e^{\left(f_{1} \tau+2 f_{2} \int v d \tau\right)}-\frac{C_{2}}{f_{1}+2 f_{2} v}\right) \frac{\left(a^{2}+b^{2}\right)}{b}=0, \\
\frac{d v}{d \tau}=\ln \left(i+\sqrt{i^{2}+1}\right) \frac{\left(a^{2}+b^{2}\right)}{2 a b}+f_{0}^{*} \sin \beta-f_{0} \cos \beta-f_{1} v-f_{2} v^{2},
\end{array}\right.
$$

а моделі оптимального руху електромобіля під час руху на підйом необхідно синтезувати з системи рівнянь

$$
\left\{\begin{array}{l}
2 a \sqrt{i^{2}+1}(1-2 \alpha i)-\left(C_{1} e^{\left(f_{1} \tau+2 f_{2} \int v d \tau\right)}-\frac{C_{2}}{f_{1}+2 f_{2} v}\right) \frac{\left(a^{2}+b^{2}\right)}{b}=0, \\
\frac{d v}{d \tau}=\ln \left(i+\sqrt{i^{2}+1}\right) \frac{\left(a^{2}+b^{2}\right)}{2 a b}-f_{0}^{*} \sin \beta-f_{0} \cos \beta-f_{1} v-f_{2} v^{2}
\end{array}\right.
$$

I ці моделі оптимального руху, які у дискретному варіанті під час руху електромобіля по горизонтальному відрізку дороги в роботі [2] отримані у вигляді (13), (14), для цієї задачі під час руху на спуск матимуть вигляд 


$$
\begin{gathered}
v_{k+1} \approx v_{k}+\frac{\left(a^{2}+b^{2}\right)}{2 a b}\left(\tau_{k+1}-\tau_{k}\right) \ln \left(i_{k}+\sqrt{i_{k}^{2}+1}\right)-\left(-f_{0}^{*} \sin \beta_{k}+f_{0} \cos \beta_{k}+f_{1} v_{k}+f_{2} v_{k}^{2}\right)\left(\tau_{k+1}-\tau_{k}\right), \\
k=0,1,2, \ldots ; \tau_{0}=0 ; v_{0}=v_{0 s} ; i_{0}=i_{0 s} ; \beta_{k} \in\left[0, \beta_{\max }<\frac{\pi}{2}\right] ; \\
i_{k}(n)=i_{k}(n-1)-\frac{C_{3}}{n}\left\{2 a \sqrt{\left(i_{k}(n-1)\right)^{2}+1}\left(1-2 \alpha i_{k}(n-1)\right)-\left(\frac{a^{2}+b^{2}}{b}\right)\left(C_{1}^{*} e^{\left(f_{1} \tau_{k}+2 f_{2} v_{k}\left(\tau_{k+1}-\tau_{k}\right)\right)}-\frac{C_{2}^{*}}{f_{1}+2 f_{2} v_{k}}\right)\right\}, \\
n=1,2, \ldots N \Rightarrow\left|i_{N-1}-i_{N}\right| \leq \varepsilon,
\end{gathered}
$$

а під час руху на підйом матимуть вигляд

$$
\begin{gathered}
v_{k+1} \approx v_{k}+\frac{\left(a^{2}+b^{2}\right)}{2 a b}\left(\tau_{k+1}-\tau_{k}\right) \ln \left(i_{k}+\sqrt{i_{k}^{2}+1}\right)-\left(f_{0}^{*} \sin \beta_{k}+f_{0} \cos \beta_{k}+f_{1} v_{k}+f_{2} v_{k}^{2}\right)\left(\tau_{k+1}-\tau_{k}\right), \\
k=0,1,2, \ldots ; \quad \tau_{0}=0 ; \quad v_{0}=v_{0 p} ; i_{0}=i_{0 p} ; \beta_{k} \in\left[0, \beta_{\max }<\frac{\pi}{2}\right] ; \\
i_{k}(n)=i_{k}(n-1)-\frac{C_{3}}{n}\left\{2 a \sqrt{\left(i_{k}(n-1)\right)^{2}+1}\left(1-2 \alpha i_{k}(n-1)\right)-\left(\frac{a^{2}+b^{2}}{b}\right)\left(C_{1}^{*} e^{\left(f_{1} \tau_{k}+2 f_{2} v_{k}\left(\tau_{k+1}-\tau_{k}\right)\right)}-\frac{C_{2}^{*}}{f_{1}+2 f_{2} v_{k}}\right)\right\}, \\
n=1,2, \ldots, N \Rightarrow\left|i_{N-1}-i_{N}\right| \leq \varepsilon,
\end{gathered}
$$

де $\tau_{0}-$ в моделях (25) відносний час початку руху на спуск, а в моделях (26) відносний час початку руху на підйом, $i_{0 s}, v_{0 s}$ - чисельні значення відносного струму та відносної швидкості на початку руху на спуск, $i_{0 p}, v_{0 p}$ - чисельні значення відносного струму та відносної швидкості на початку руху на підйом, а $\varepsilon$ - задане чисельне значення похибки обчислень, від якого залежить кількість ітерацій $N$ при визначенні чисельних значень відносного струму $i_{k}$ на кроці $k$.

\section{Аналіз отриманих результатів}

Аналізуючи дискретні математичні моделі (25), (26), якими задаються закони оптимального руху електромобіля на спуск та на підйом, бачимо, що для запуску ітераційних алгоритмів, за якими обчислюється кожне наступне оптимальне значення відносної швидкості електромобіля та відносного струму його тягового електродвигуна, необхідно знати числові значення відносного струму $i_{0}$ та відносної швидкості $v_{0}$ на початку руху на спуск $\left(i_{0 s}, v_{0 s}\right)$ чи на підйом $\left(i_{0 p}, v_{0 p}\right)$, а також числові значення констант $C_{1}^{*}, C_{2}^{*}, C_{3}$. А в процесі реалізації ітераційних алгоритмів в моделях (25), (26) необхідно знати на кожному кроці $k$ ще й числове значення кута нахилу $\beta_{k}$ осі дороги (або, що те саме, поздовжньої осі рами електромобіля) до горизонтальної площини.

Від константи $C_{3}$ залежить швидкість руху ітераційного процесу до «нерухомої точки», тож іï числове значення вибираємо враховуючи, що більшим одиниці воно може бути лише за умови, коли оцінки відносного струму на кожному кроці до «нерухомої точки» наближаються монотонно. Якщо ж процес цього наближення $є$ знакозмінним, то краще задавати значення цієї константи рівним одиниці.

Що ж до констант $C_{1}^{*}, C_{2}^{*}$, то тут їх уже не можна обчислювати за виразами (9), (10), оскільки у цьому випадку змінюються граничні умови, які тепер уже не матимуть вигляд виразів (11), (12), а задаватимуться виразами

$$
\left\{\begin{array}{l}
i(0)=i_{0}, \\
v(0)=v_{0}, \\
\int_{0}^{0} v(\tau) d \tau=0
\end{array}\right.
$$




$$
\left\{\begin{array}{l}
v^{\prime}\left(\tau_{l}\right)=v_{l}^{\prime}, \\
v\left(\tau_{l}\right)=v_{l}, \\
\int_{0}^{\tau_{l}} v(\tau) d \tau=l,
\end{array}\right.
$$

в яких числові значення $i_{0}, v_{0}$ відносного струму та відносної швидкості в точці входження в спуск чи підйом вимірятимемо, а числові значення $v_{l}, v_{l}^{\prime}$ відносної швидкостіі та прискорення в точці закінчення спуску чи підйому задаватимемо, аби саме за цих їхніх значень завершувати спуск чи підйом.

Накладемо умову, що зі спуску чи підйому електромобіль виїздить на горизонтальний відрізок дороги, тобто, що

$$
\beta_{l}=0 .
$$

3 урахуванням умов (28) та (29) з другого рівняння системи (24) матимемо:

$$
v_{l}^{\prime}=\ln \left(i_{l}+\sqrt{i_{l}^{2}+1}\right) \frac{a^{2}+b^{2}}{2 a b}-f_{0}-f_{1} v_{l}-f_{2} v_{l}^{2},
$$

а з виразу (30) після відповідних перетворень знайдемо, що відносний струм $i_{l}$ тягового електродвигуна електромобіля в точці виїзду зі спуску чи підйому на горизонтальну ділянку дороги, тобто, в момент відносного часу $\tau_{l}$, для забезпечення заданих умовами (28) числових значень відносної швидкості $v_{l}$ та прискорення $v_{l}^{\prime}$ можна заздалегідь визначити, трансформувавши вираз (30) до вигляду

$$
i_{l}=\frac{e^{2 v_{\Sigma}}-1}{2 e^{v_{\Sigma}}}
$$

в якому

$$
v_{\Sigma}=\frac{2 a b}{a^{2}+b^{2}}\left(v_{l}^{\prime}+f_{0}+f_{1} v_{l}+f_{2} v_{l}^{2}\right) .
$$

А далі, підствляючи умови (27) в перше рівняння системи (24), отримаємо:

$$
2 a \sqrt{i_{0}^{2}+1}\left(1-2 \alpha i_{0}\right)-\left(C_{1}-\frac{C_{2}}{f_{1}+2 f_{2} v_{0}}\right) \frac{\left(a^{2}+b^{2}\right)}{b}=0,
$$

У свою чергу, з виразу (33) матимемо

$$
C_{1}=\frac{2 a b}{a^{2}+b^{2}}\left(1-2 \alpha i_{0}\right)+\frac{C_{2}}{f_{1}+2 f_{2} v_{0}} .
$$

А підставляючи вираз (34) та умови (28) і результат розрахунку за виразом (31) в перше рівняння системи (24) та здійснюючи відповідні перетворення, отримаємо:

де

$$
\begin{gathered}
C_{2}=\frac{2 a b\left(f_{1}+2 f_{2} v_{0}\right)\left(f_{1}+2 f_{2} v_{l}\right) \phi\left(i_{0}, i_{l}\right)}{\left(a^{2}+b^{2}\right)\left[\left(f_{1}+2 f_{2} v_{l}\right) \exp \left(f_{1} \tau_{l}+2 f_{2} l\right)-f_{1}-2 f_{2} v_{0}\right]}, \\
\phi\left(i_{0}, i_{l}\right)=\sqrt{i_{l}^{2}+1}\left(1-2 \alpha i_{l}\right)-\left(1-2 \alpha i_{0}\right) \exp \left(f_{1} \tau_{l}+2 f_{2} l\right) .
\end{gathered}
$$

Порівнюючи вирази (9), (10) та (34), (35), видно, що вони суттєво відрізняються, а тому відрізнятимуться і ітераційні процедури (13), (14) та (25), (26), в яких використовуються константи, що обчислюються за цими виразами.

Але ітераційні процедури (25), (26) та (13), (14) відрізняються не лише різними значеннями згаданих вище констант - вони відрізняються ще й тим, що в ітераційних процедурах (25), (26) використовується кут $\beta$ нахилу поздовжньої осі рами електромобіля до горизонтальної площини, 
який змінюється в процесі руху електромобіля на спуск чи на підйом дороги, що вимагає встановлення на електромобілях присторїв для вимірювання цього кута. Але, оскільки станом на сьогодні вже сконструйовано і випускається промисловістю достатньо багато таких пристроїв, як електромеханічних так і оптикоелектронних та гіроскопічних, приклади встановлення окремих зразків яких на автомобілях уже мають місце, то не стане нерозв'язною і проблема вимірювання кута нахилу поздовжньої осі рами електромобіля до горизонтальної площини в темпі процесу його зміни під час руху на спуск чи на підйом. А це дає надію автору вищесинтезованих дискретних математичних моделей оптимального руху електромобіля на спуск чи на підйом, що ці моделі досить швидко будуть втіленими творцями сучасних електромобілів в системах керування ними.

I, завершуючи цей аналіз, автор зверає увагу на те, що в разі, якщо електромобіль виїжджає на горизонтальну ділянку дороги зі спуску чи підйому без зупинки, то для визначення констант в моделях його оптимального руху теж стають непридатними вирази (9), (10), оскільки граничні умови не можуть бути заданими у вигляді (11), (12), а вони матимуть або вигляд (27), (28), або наближатимуться до них за своєю структурою, що приведе нас і у цьому випадку до виразів (34), (35) для визначення констант, або до виразів, подібних їм за своєю структурою.

\section{Висновки}

В розвиток методу синтезу та ідентифікації моделей оптимального руху електромобіля з асинхронним електроприводом по горизонтальному відрізку дороги запропоновано метод синтезу та ідентифікації моделей оптимального руху електромобіля з аналогічним електроприводом, але під час руху на спуск та на підйом, за яким, як і за базовим методом, на першому етапі реалізації визначаються константи, які мають місце у цих моделях внаслідок використання двічі операції інтегрування в процесі їхнього синтезу, але з використанням граничних умов, що суттєво відрізняються від використаних в базовому методі, та іншої послідовності використання цих граничних умов. А на другому етапі реалізації, як і у базовому методі, теж пропонується прямий алгоритм визначення швидкості електромобіля на основі моделі його динаміки, але з використанням попередньо ітераційно обчислених значень оптимального струму, пов'язаного зі швидкістю електромобіля співвідношенням, отриманим, як і у базовому методі, в результаті розв'язання задачі оптимізації методом невизначених множників Лагранжа, та з використанням ще й виміряних відповідним пристроєм кутів нахилу поздовжньої осі рами електромобіля до горизонтальної площини, які під час руху на спуск та на підйом не залишаються незмінними, та які не використовуються в базовому методі.

\section{СПИСОК ВИКОРИСТАНОÏ ЛІТЕРАТУРИ}

[1] Б. І. Мокін, О. Б. Мокін, і В. В. Горенюк, «До питання оптимізації руху електромобіля з асинхронним електроприводом,» Вісник Вінницького політехнічного інституту, № 3, с. 32-38, 2019.

[2] Б. І. Мокін, О. Б. Мокін, і В. В. Горенюк, «Метод ідентифікації моделей оптимального руху електромобіля 3 асинхронним електроприводом,» Вісник Вінницького політехнічного інституту, №1, с. 32-38, 2020.

[3] Я. З. Цыпкин, Адаптация и обучение в автоматических системах. Москва: Наука, 1968, 400 с.

[4] В. А. Лобатюк, О. Б. Мокін, і Б. І. Мокін, Математичні моделі оптимального руху електромобілів з електроприводом постійного струму. Вінниця, Україна: ВНТУ, 2019.

Рекомендована кафедрою електромеханічних систем автоматизації в промисловості і на транспорті ВНТУ

Стаття надійшла до редакції 31.03.2021

Горенюк Вадим Вікторович - аспірант кафедри електромеханічних систем автоматизації в промисловості і на транспорті, e-mail: gvv.ghost@gmail.com .

Вінницький національний технічний університет, Вінниця 
V. V. Horeniuk ${ }^{1}$

\title{
Synthesis and Identification of Optimal Motion Models of an Electric Car with an Induction Traction Motor on the Slopes and Rises of the Road
}

\begin{abstract}
${ }^{1}$ Vinnytsia National Technical University
The optimal motion's models synthesis and identification method of an electric car with a traction induction motor during the road on the descent and ascent is proposed, which uses the same approach as we proposed during the development of the synthesis and identification method of optimal motion's models of an electric car with traction induction motor on a horizontal section of road, but with different boundary conditions, with a different their using procedure to determine constants which take place in these models due to the use of double integration operations in the process of their synthesis by the method of indefinite Lagrange multipliers and also with other procedure of realization of direct algorithm of definition of speed of the electric car on the basis of model of its dynamics, which in the case of movement on descent and ascent as parameters also includes the angle of the electric car frame longitudinal axis inclination to the horizontal plane, which one is a variable in space, so for a moving electric car this value is variable in time, and therefore requires measurement by an appropriate device. Also shown that if the electric car goes on the horizontal section of the road from descent or ascent without stopping, then to determine the constants in the models of its optimal movement of the horizontal section of the road become unsuitable expressions that we obtained earlier for the case, when electric car optimal motion models by the horizontal section of the road from stop to stop were determined, because the boundary conditions change, and therefore the expressions by which these constants are determined become similar in structure to those obtained by us in this article for models of optimal electric car movement on descent or ascent.
\end{abstract}

Keywords: electric car, motion on descent and ascent, optimization, model, identification, method, iterative algorithm.

Horeniuk Vadym V. - Post-Graduate Students of the Chair of Electromechanical Systems Automation in Industry and Transport, email: gvv.ghost@gmail.com

В. В. Горенюк ${ }^{1}$

\section{Синтез и идентификация моделей оптимального движения электромобиля с асинхронным электроприводом по склонам и подъемам дороги}

\author{
${ }^{1}$ Винницкий национальный технический университет
}

\begin{abstract}
Предложен метод синтеза и идентифрикации моделей оптимального движения электромобиля с асинхронным электроприводом при движении по дороге на спуск и на подъем, в котором использован подход, предложенный при разработке метода синтеза и идентификации моделей оптимального движения электромобиля с асинхронным электроприводом по горизонтальному отрезку дороги, но с другими граничными условиями, с другой процедурой их использования для определения констант, которые имеют место в этих моделях в результате использования дважды операции интегрирования в процессе их синтеза методом неопределенных множителей Лагранжа, а также с другой процедурой реализации прямого алгоритма определения скорости электромобиля на основе модели его динамики, которая в случае движения на спуск и на подъем в качестве параметров включает в себя еще и угол наклона продольной оси рамы электромобиля к горизонтальной плоскости, который является величиной переменной в пространстве, поэтому для движущегося электромобиля является величиной переменной и во времени, а потому требует измерения соответствующим устройством. Показано также, что в случае, если электромобиль выезжает на горизонтальный участок дороги со спуска или подъема без остановки, то для определения констант в моделях его оптимального движения горизонтальным участком дороги стают непригодными выражения, полученные ранее для случая, когда определялись модели оптимального движения электромобиля горизонтальным участком дороги от остановки к остановке, поскольку меняются граничные условия, а потому и выражения, по которым определяются эти константы становятся по своей структуре приближенными к тем, которые получены в этой статье для моделей оптимального движения электромобиля на спуск или подъем.
\end{abstract}

Ключевые слова: электромобиль, движение на спуск и на подъем, оптимизация, модель, идентификация, метод, итерационный алгоритм.

Горенюк Вадим Викторович - аспирант кафедры электромеханических систем автоматизации в промышленности и на транспорте, e-mail: gvv.ghost@gmail.com 